Dokuz Eylül Üniversitesi-Mühendislik Fakültesi

Fen ve Mühendislik Dergisi

Cilt 19, Sayı 57, Eylül 2017
Dokuz Eylul University-Faculty of Engineering Journal of Science and Engineering Volume 19, Issue 57, September 2017

DOI: $10.21205 /$ deufmd.2017195780

\title{
Bending Analysis of Bilaterally Clamped Thick Cross-Ply Composite Plates
}

\author{
Veysel ALANKAYA*1
}

${ }^{1}$ Milli Savunma Üniversitesi, Deniz Harp Okulu, Gemi İnşaatı Müh.Bölümü, 34942, İstanbul

(Alınıș / Received: 22.02.2017, Kabul / Accepted: 14.04.2017, Online Yayınlanma / Published Online: 20.09.2017)

Keywords

Analytical solution, Cross-ply plates, Fourier analysis, Higher order shear deformation theory

\begin{abstract}
Bending deformation of composite plates is consistent investigation by means of varying boundary conditions and laminations. In this study bending analysis of laminated composites which has clamped boundaries at bilateral edges while the other opposites are free are investigated by a new analytical solution methodology based on third order shear deformation theory. The aim of this study is to present the analytical methodology for an unsolved boundary condition result in a gap in the literature. Double Fourier series are used to solve highly coupled linear partial differential equations for the clamped boundary conditions prescribed on the edges. The complementary boundary constraints are introduced through discontinuities at the boundaries which are generated by the selected boundary conditions, resulting in the derivation of the complementary solution. The numerical results of the new model is compared by the counterparts obtained by finite element analyses.
\end{abstract}

\section{Karşılıklı Kenarları Ankastre Çapraz Dizilimli Kalın Kompozit Plakların Eğilme Analizi}

\begin{abstract}
Anahtar Kelimeler Özet: Kompozit plakların farklı sınır şartları ve dizilimler etkisi Analitik çözüm, Çapraz dizilimli plaklar, Fourier analizi, Yüksek mertebeli kayma deformasyon teorisi altında eğilme deformasyonu süregelen bir araștırma konusudur. Bu çalışmada, karşılıklı iki kenarı ankastre diğer kenarları serbest sınır şartlarına sahip lamine kompozitlerin eğilme deformasyonu üçüncü mertebeden kayma deformasyon teorisine dayanan bir analitik çözüm yöntemi ile incelenmiștir. Bu çalıșmanın amacı halen literatürde bir boşluk oluşturan çözülmemiş sınır șartları için analitik bir çözüm metodu sunmaktır. Karşılıklı kenarlar için tariflenen ankastre sınır şartı için yüksek mertebeli kısmi diferansiyel denklem çözümlerinde çift Fourier serileri kullanılmıştır. Tanımlanmış sınır şartları etkisiyle çözümde oluşan süreksizlikler sınırlarda tanımlanmış katsayılar ile çözüme dahil edilmiştir. Yeni modelin sonuçları sonlu elemanlar yöntemi analizleri ile elde edilen muadilleri ile karşılaştırılmıştır.
\end{abstract}




\section{Introduction}

Composite materials have been introduced as the futuristic solutions of the revolutionary designs for various industries. However due to their complex deformation behavior, they constrain designers with the problems of understanding the various interactions among different deformations such as warping which is the bending-stretching coupling due to asymmetry of lamination, inter-laminar or transverse shear stress due to mismatch of material properties among layers and in-plane orthotrophy. Satisfying the specific boundary conditions is another problem in the static analysis because discontinuities in the structure may show incorrect results at the junction points which affect the overall solution procedure. Even though the design flexibility inherent in composite laminates caused them to be more preferable, any changes in the combination of structural/material concepts, stacking sequence, ply orientation, etc. result in significant differences in the stiffness of the structure. It is crucially important to know that every change in design variables require a different solution procedure and affect the performance of composite laminates in various combinations. It is also important to have appropriate techniques associated with good structural models to analyze the effects of design sensitivities efficiently and accurately [1].

The transverse stress and strain components are ignored in classical plate or shell theories which makes them highly inadequate for the analysis of moderately thick and thick plates. Higher order theories which do not need the shear correction factor are highly advantageous especially in predicting the response for thick structures [2-4]. Higher order theories enable designers to achieve an increased accuracy and reliability of deformations and stresses for thick structures $[1,5]$.

There has been a consistent study in developing new and more accurate higher order theories. Many different functions can be suggested for the deformation of the structure such as exponential, polynomial, logarithmic, hyberbolic, paraboloic and so on. Alipour [6] made an analytical approach to bending analysis for both angle-ply and cross-ply laminated composites under arbitrary loads and elastic foundations. Raghu et.al. [7] used the theory of nonlocal continuum mechanics and Reddy's third order shear deformation theory to provide an analytical approach for laminated plates considering surface stress on deflections. Refined theories such as zigzag layer wise theory, DQM (differential quadrature method) and finite strip method are also used by various authors. Sarangan and Singh [8] suggested a higher-order closed-form solution by analyzing algebraic, exponential, hyperbolic, logarithmic and trigonometric theories for sandwich plates. They also developed an improved zigzag theory [9] for laminated composites and sandwich plates with interlaminal shear stress continuities.

Kurtaran [10] performed a geometrically nonlinear transient analysis of moderately thick laminated composite shells using DQM. Semi analytical finite strip method is developed by Cheung [11] and is widely used by other authors $[12,13]$. This method can handle simple boundary conditions such as simply supported-simply supported and clamped-clamped. However, for more complex boundary conditions, different approaches need to be utilized.

Due to the nature of analytical solution, most of the current and previous works have significant number of simplifying assumptions. Since the solution to the 
fully developed 3D equations of elasticity is highly complex, most analytical solutions can only be applied to simple geometric structures [14]. Thus, various theories needed to be utilized in order to determine the kinematics of deformation and stresses alongside the thickness of the laminate [15]. Common approaches such as Navier or Levy cannot solve the complexities in the analytical solution caused by the discontinuities in the boundaries. A novel discontinuous double fourier series approach is one of the ways to overcome this phenomenon which was presented by Chaudhuri [16, 17].

In this study, an analytical solution has been proposed for composite laminated plates having two clamped edges while the others are free. Complementary solution functions are introduced to the solution methodology to overcome the discontinuties result by arbitrary boundary conditions. Thus, a mathematical model has been developed for cross-ply laminated composite plates under uniformly distributed load and compared with finite element results in order to validate its accuracy. The results found are in very good agreement with the finite element counterparts. After the validation, displacements and stresses for the laminated plate are presented in order to provide benchmark results for future work.

\section{Material and Method}

The geometry of a composite plate consist of cross-ply layers with uniform thicknesses is shown in Figure 1, where $a$ and $b$ represent the dimensions through $\left(\xi_{1}, \xi_{2}\right)$ axis respectively while $\left(\xi_{3}\right)$ is a straight line normal to the mid-surface defined at the center through the plate thickness represented by $h$.

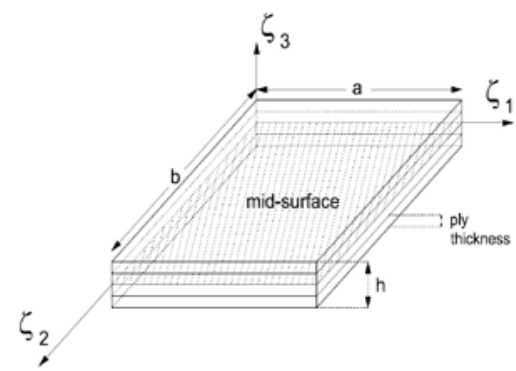

Figure 1. The geometry of a laminated composite plate

The displacement field as considered cubic terms while satisfying the conditions for transverse shear stresses (and hence strains) vanishing on the top and bottom surfaces of the shell, is given by as follows [18]:

$$
\begin{aligned}
& u_{1}=u\left(\xi_{1}, \xi_{2}, \xi_{3}\right)=u_{0}\left(\xi_{1}, \xi_{2}\right) \\
&+ z \phi_{1}\left(\xi_{1}, \xi_{2}\right)-\frac{4}{3 h^{2}} z^{3}\left(\phi_{1}+\frac{\partial w_{0}}{\partial \xi_{1}}\right) \\
& u_{2}=v\left(\xi_{1}, \xi_{2}, \xi_{3}\right)=v_{0}\left(\xi_{1}, \xi_{2}\right) \\
&+z \phi_{2}\left(\xi_{1}, \xi_{2}\right)-\frac{4}{3 h^{2}} z^{3}\left(\phi_{2}+\frac{\partial w_{0}}{\partial \xi_{2}}\right) \\
& u_{3}=w\left(\xi_{1}, \xi_{2}, \xi_{3}\right)=w_{0}\left(\xi_{1}, \xi_{2}\right)
\end{aligned}
$$

where $u, v, w$ represents displacements of a point at three axis $\left(\xi_{1}, \xi_{2}, \xi_{3}\right)$, while $u_{0}, v_{0}, w_{0}$ represents displacements of a point at the mid-surface $\left(\xi_{3}=0\right)$. The distance of the ply from the mid-surface and the thickness of the plate are represented by ( $z$ ) and (h) respectively. $\phi_{1}$ and $\phi_{2}$ are rotations about $\left(\xi_{2}\right)$ and $\left(\xi_{1}\right)$ axes. 
The equilibrium equations derived using the principles of virtual work [18] and constitutive equations are given in Appendix-A in detail. Finally expanding the elasticity tensor (stiffness matrix) components into the equilibrium equations introduce five highly coupled fourth order partial differential equations. The set of equations can be expressed in the following form:

$$
\left[\begin{array}{lllll}
K_{11} & K_{12} & K_{13} & K_{14} & K_{15} \\
K_{21} & K_{22} & K_{23} & K_{24} & K_{25} \\
K_{31} & K_{32} & K_{33} & K_{34} & K_{35} \\
K_{41} & K_{42} & K_{43} & K_{44} & K_{45} \\
K_{51} & K_{52} & K_{53} & K_{54} & K_{55}
\end{array}\right]\left\{\begin{array}{l}
u_{1} \\
u_{2} \\
u_{3} \\
\phi_{1} \\
\phi_{2}
\end{array}\right\}=\left\{\begin{array}{c}
0 \\
0 \\
Q_{m n} \\
0 \\
0
\end{array}\right\}
$$

The definitions of $\left[K_{i j}\right]$ elements for the general anisotropic case are given in Appendix-B and the load term $Q_{m n}$ is defined as follows for uniformly distributed load:

$$
Q_{m n}=-\frac{16 q}{\pi^{2} m n}
$$

\section{Solution Methodology}

The boundaries for the problem under consideration are graphically shown in Figure 2, where they can be described as clamped at $\xi_{1}=0, a$ and free at $\xi_{2}=0, b$.

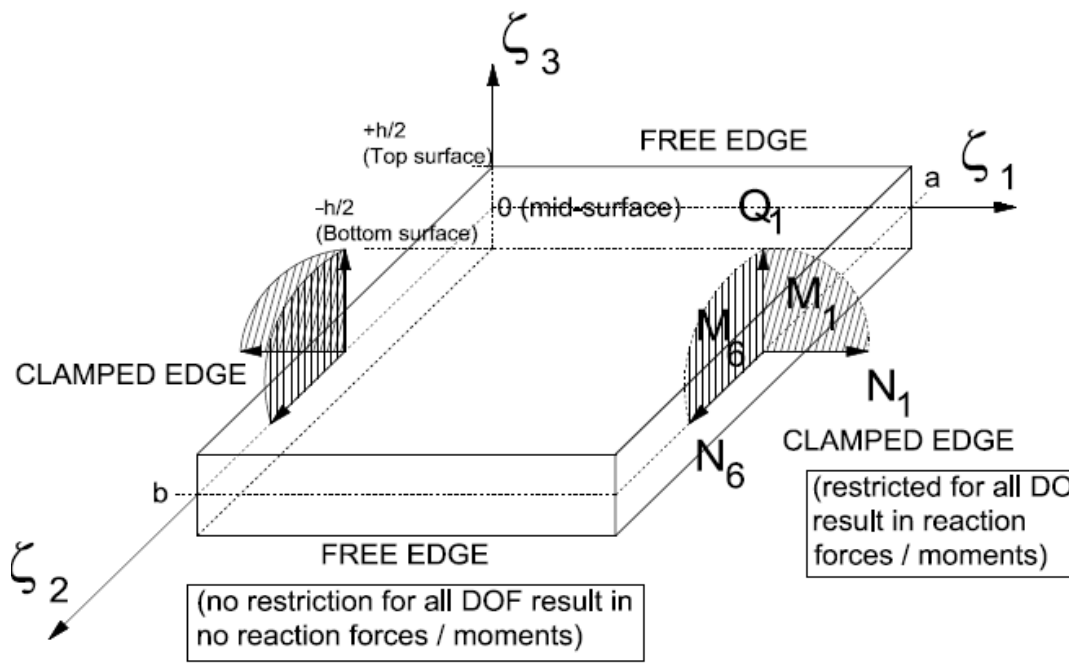

Figure 2. Boundary conditions of the plate.

The following boundary conditions can be defined according to prescribed restrictions;

$$
\begin{aligned}
& u_{1}=u_{2}=u_{3}=\phi_{1}=\phi_{2}=0 \\
& \text { for } \xi_{1}=0, a \\
& N_{2}=N_{6}=Q_{2}=M_{2}=M_{6}=0 \\
& \text { for } \xi_{2}=0, b
\end{aligned}
$$

Prescribed boundary conditions cannot be handled neither by Navier's nor by Levy's conventional analytical approaches. Thus it is needed to establish a solution methodology dealing with the additional complexities arise by way of satisfying boundary conditions. The particular solution to the boundaryvalue problem is assumed as follows with the amplitudes of $U_{m n}, V_{m n}$ and $W_{m n}$ at $\xi_{1}, \xi_{2}, \xi_{3}$ axes and $X_{m n}, Y_{m n}$ for $\phi_{1}$ and $\phi_{2}$ rotations about $\xi_{2}$ and $\xi_{1}$ axes respectively.

$$
u_{1}\left(\xi_{1}, \xi_{2}\right)=\sum_{m=0}^{\infty} \sum_{n=1}^{\infty} U_{m n} \Re_{1}\left(\xi_{1}, \xi_{2}\right)
$$




$$
\begin{aligned}
& 0<\xi_{1}<a ; 0<\xi_{2}<b \\
& \hline u_{2}\left(\xi_{1}, \xi_{2}\right)=\sum_{m=1}^{\infty} \sum_{n=0}^{\infty} V_{m n} \Re_{2}\left(\xi_{1}, \xi_{2}\right) \\
& 0 \leq \xi_{1} \leq a ; 0 \leq \xi_{2} \leq b \\
& \hline u_{3}\left(\xi_{1}, \xi_{2}\right)=\sum_{m=1}^{\infty} \sum_{n=1}^{\infty} W_{m n} \Re_{3}\left(\xi_{1}, \xi_{2}\right) \\
& 0 \leq \xi_{1} \leq a ; 0<\xi_{2}<b \\
& \hline \phi_{1}\left(\xi_{1}, \xi_{2}\right)=\sum_{m=0}^{\infty} \sum_{n=1}^{\infty} X_{m n} \Re_{1}\left(\xi_{1}, \xi_{2}\right) \\
& 0<\xi_{1}<a ; 0<\xi_{2}<b \\
& \phi_{2}\left(\xi_{1}, \xi_{2}\right)=\sum_{m=1}^{\infty} \sum_{n=0}^{\infty} Y_{m n} \Re_{2}\left(\xi_{1}, \xi_{2}\right) \\
& 0 \leq \xi_{1} \leq a ; 0 \leq \xi_{2} \leq b
\end{aligned}
$$

where;

$$
\begin{aligned}
& \Re_{1}\left(\xi_{1}, \xi_{2}\right)=\cos \left(\alpha \xi_{1}\right) \sin \left(\beta \xi_{2}\right), \\
& \Re_{2}\left(\xi_{1}, \xi_{2}\right)=\sin \left(\alpha \xi_{1}\right) \cos \left(\beta \xi_{2}\right), \\
& \mathfrak{R}_{3}\left(\xi_{1}, \xi_{2}\right)=\sin \left(\alpha \xi_{1}\right) \sin \left(\beta \xi_{2}\right), \\
& \alpha=\frac{m \pi}{a}, \beta=\frac{n \pi}{b}
\end{aligned}
$$

The next step is substituting assumed particular solutions into equilibrium equations. The procedure for differentiation of these functions has been presented by Chaudhuri [18] who introduced the boundary coefficients to serve as complementary solution to the problem under investigation. The partial derivatives which cannot be achieved by term wise differentiation are presented in Eqs (7-9), the remaining partial derivatives can be obtained by term wise differentiation. The unknown boundary Fourier coefficients appear in Eqs. (7-9) are defined in Eqs. (11).

Expanding assumed Fourier series results in a system of equations consisting of the unknown boundary Fourier coefficients presented in Eq. (11). Therefore remaining equations which are needed to determine these unknown terms are supplied by the boundary conditions. The geometric boundary conditions relating to $u_{1}, u_{2}, u_{3}, \phi_{1}, \phi_{2}$ for the edges $\left(\xi_{1}=0, a\right)$, and the natural boundary conditions relating to $N_{6}, N_{2}, M_{6}, M_{2}, Q_{2}$ at the edges $\left(\xi_{2}=0, b\right)$ provide the set of solution equations.

\section{Numerical Results and Discussions}

Numerical results are presented for symmetric and antisymmetric cross-ply square $(a=b)$ plates which are subjected to uniformly distributed load. The material characteristics are defined as linearly changing, purposing to demonstrate the effects of material properties, for the numerical results. The assumed material properties are presented in the Table 1. 


$$
\begin{aligned}
& \left|\begin{array}{l}
u_{1,11} \\
\phi_{1,11}
\end{array}\right|=\frac{1}{2} \sum_{n=1}^{\infty} \bar{a}_{n} \sin \left(\beta \xi_{2}\right)+\sum_{m=0}^{\infty} \sum_{n=1}^{\infty}\left(-\alpha^{2}\left|\begin{array}{l}
U_{m n} \\
X_{m n}
\end{array}\right|+\bar{a}_{n} \gamma_{m}+\bar{b}_{n} \delta_{m}\right) \cos \left(\alpha \xi_{1}\right) \sin \left(\beta \xi_{2}\right) \\
& \left|\begin{array}{l}
u_{1,22} \\
\phi_{1,22}
\end{array}\right|=-\frac{1}{2} \sum_{n=1}^{\infty} \beta\left(\beta\left|\begin{array}{l}
U_{0 n} \\
X_{0 n}
\end{array}\right|+\bar{a}_{0} \gamma_{n}+\bar{b}_{0} \delta_{n}\right) \sin \left(\beta \xi_{2}\right) \\
& -\sum_{m=0}^{\infty} \sum_{n=1}^{\infty}\left(\beta\left|\begin{array}{l}
U_{m n} \\
X_{m n}
\end{array}\right|+\bar{c}_{m} \gamma_{n}+\bar{d}_{m} \delta_{n}\right) \cos \left(\alpha \xi_{1}\right) \sin \left(\beta \xi_{2}\right) \\
& u_{3,2}=\frac{1}{2} \sum_{m=1}^{\infty} \bar{e}_{m} \sin \left(\alpha \xi_{1}\right)+\sum_{m=1}^{\infty} \sum_{n=1}^{\infty}\left[\beta W_{m n}+\gamma_{n} \bar{e}_{m}+\psi_{n} \bar{f}_{m}\right] \sin \left(\alpha \xi_{1}\right) \cos \left(\beta \xi_{2}\right) \\
& \text { in which; } \quad\left(\gamma_{n}, \psi_{n}\right)= \begin{cases}(0,1), & n=\text { odd }, \\
(1,0), & n=\text { even } .\end{cases} \\
& \bar{a}_{n}, \bar{b}_{n}=\frac{4}{a b} \int_{0}^{b}\left[ \pm u_{1,1}\left(a, \xi_{2}\right)-u_{1,1}\left(0, \xi_{2}\right)\right] \sin \left(\beta \xi_{2}\right) d \xi_{2} \\
& \bar{c}_{m}, \bar{d}_{m}=\frac{4}{a b} \int_{0}^{a}\left[ \pm u_{1}\left(\xi_{1}, b\right)-u_{1}\left(\xi_{1}, 0\right)\right] \cos \left(\alpha \xi_{1}\right) d \xi_{1} \\
& \bar{e}_{m}, \bar{f}_{m}=\frac{4}{a b} \int_{0}^{a}\left[ \pm u_{3}\left(\xi_{1}, b\right)-u_{3}\left(\xi_{1}, 0\right)\right] \sin \left(\alpha \xi_{1}\right) d \xi_{1}
\end{aligned}
$$

\begin{tabular}{|c|c|c|c|c|c|c|}
\hline $\begin{array}{l}\text { Mat. } \\
\text { No. }\end{array}$ & $\begin{array}{c}E_{1} \\
(G P a)\end{array}$ & $\begin{array}{l}E_{1} \\
/ \\
E_{2}\end{array}$ & $\begin{array}{l}G_{12} \\
/ E_{2} \\
\end{array}$ & $\begin{array}{l}G_{13} \\
/ E_{2}\end{array}$ & $\begin{array}{c}G_{23} / \\
E_{2}\end{array}$ & $v_{12}$ \\
\hline I & 100 & 25 & 0.5 & 0.5 & 0.2 & 0.15 \\
\hline II & 250 & 25 & 0.5 & 0.5 & 0.2 & 0.40 \\
\hline III & 100 & 10 & 1 & 1 & 0.35 & 0.15 \\
\hline IV & 250 & 10 & 1 & 1 & 0.35 & 0.40 \\
\hline
\end{tabular}

Table 1. Assumed material properties for the numerical results.

Here $E_{1}$ and $E_{2}$ are the in-plane Young's moduli in $\xi_{1}$ and $\xi_{2}$ coordinate axis respectively, while $G_{12}$ denotes in-plane shear modulus. $G_{13}$ and $G_{23}$ are transverse shear moduli in the $\left(\xi_{1}-\xi_{3}\right)$ and $\left(\xi_{2}-\xi_{3}\right)$ planes, respectively, while $v_{12}$ is major Poisson's ratio on the $\left(\xi_{1}-\xi_{2}\right)$ plane.

In the calculations, the following normalized quantities are defined in which ' $a \& b$ ' is the edge length of the panel, and $q_{0}$ denotes the transverse load. The normalized quantities are computed for all the numerical results presented in all figures.

$$
\begin{aligned}
& u_{3}^{*}=\left(10^{3} E h^{3} / q_{0} a^{4}\right) u_{3} \\
& M_{1}^{*}=\left(10^{3} / q_{0} a^{2}\right) M_{1} \\
& \sigma_{1}^{*}=10\left(h^{2} / q_{0} b^{2}\right) \sigma_{1} \\
& \sigma_{2}^{*}=10\left(h^{2} / q_{0} b^{2}\right) \sigma_{2}
\end{aligned}
$$

It is needed to define the number of terms to be included in the equations for this solution methodology. Therefore, Figure 3 displays the convergence of normalized central transverse displacement $\left(u_{3}{ }^{*}\right)$ and moment $\left(M_{1}^{*}\right)$ of a thick $(a / h=10)$ plate which has symmetrical cross-ply lamination of $\left[0^{\circ}, 90^{\circ}, 90^{\circ}, 0^{\circ}\right]$ under uniformly distributed load. 


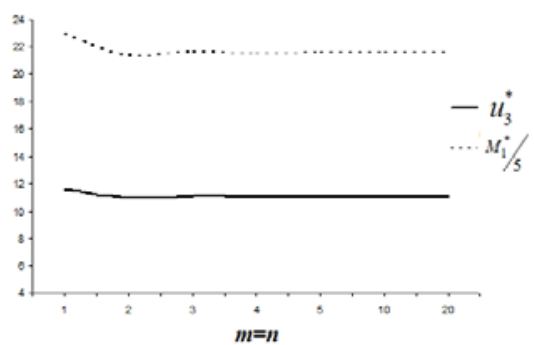

Figure 3. Convergence control of the solution methodology.

The normalized displacement $\left(u_{3}{ }^{*}\right)$ and moment $\left(M_{1}^{*}\right)$ values exhibit a fast convergence where 20 terms are included in the expansion of double Fourier series. Consequently, number of terms are defined as $n=m=20$ for numerical results.

\subsection{Validation of the Present Solution}

Finite element analyses are performed by a commercially available FEA software ANSYS ${ }^{\mathrm{TM}}$ for the validation of the presented solution methodology. Composite plate with symmetrical cross-ply lamination of $\left[0^{\circ}, 90^{\circ}, 90^{\circ}, 0^{\circ}\right]$ under uniformly distributed load is modeled as presented in Figure 4.

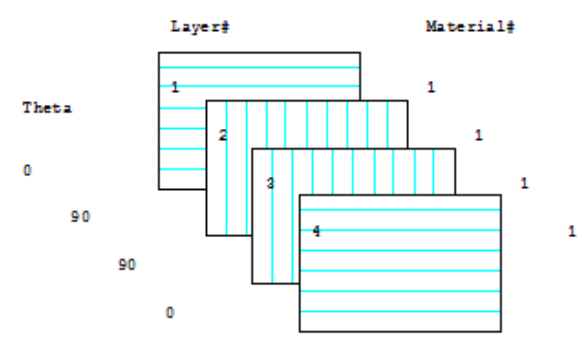

Figure 4. Layer definitions for the Shell 91 element.

The present study is mainly focused on the effects of shear deformations which are more efficient in the thick and moderately thick regime. Therefore, Shell-91 element is used which is developed for modeling thick sandwich structures and layered applications of structural shells.

Shell-91 element type with 8 nodes and six degree of freedom is suitable for nonlinear layered structural shell analyses with sandwich option. Because the chosen element type is considered for comparison purposes on meso-scale level, each ply is modeled and analyzed having one element per ply as presented in the Figure 5.

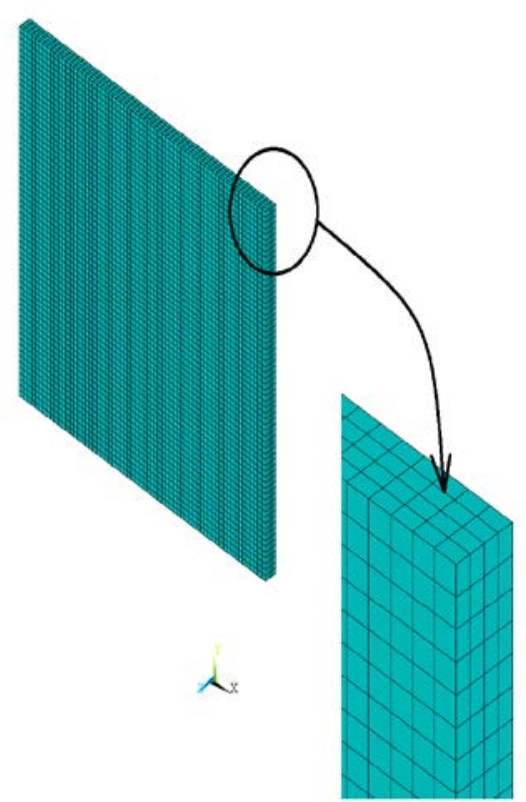

Figure 5. The element description for the FEA model.

Table 2. Comparison of the central deflections obtained from present theory with their FEA counterparts.

\begin{tabular}{|c|c|c|}
\hline \multirow{2}{*}{$\boldsymbol{a} / \boldsymbol{h}$} & \multicolumn{2}{|c|}{ Central Deflection $\left(\mathbf{u}_{3}\right)[\mathrm{mm}]$} \\
\cline { 2 - 3 } & $\begin{array}{c}\text { Present } \\
\text { Theory }\end{array}$ & FEA \\
\hline $\mathbf{4}$ & 0.001473 & 0.001715 \\
\hline $\mathbf{5}$ & 0.002173 & 0.002385 \\
\hline $\mathbf{1 0}$ & 0.008902 & 0.008787 \\
\hline $\mathbf{2 0}$ & 0.051112 & 0.049696 \\
\hline
\end{tabular}


The numerical results of FEA and presented theory for laminated composite plate which has symmetrical cross-ply lamination of $\left[0^{\circ}, 90^{\circ}, 90^{\circ}, 0^{\circ}\right]$ and MAT-I material properties are presented in Table 2 for comparison purposes.

The numerical results of the presented theory are in concordance with FEA counterparts and indicate that it is adequately sensitive on thickness changes of laminated plies.

\subsection{Numerical Results and Discussions}

Numerical results are obtained to present the effects of material properties, lamination symmetry and ply thickness. Therefore material properties are linearly changed as described in Table.1 for both symmetric and anti-symmetric lamination. The variable of ply thickness ratio $(a / h)$ is assumed to be in thick $(a / h<10)$ and moderately thick $(10 \leq a / h \leq 20)$ regime in the calculations aiming to demonstrate its effect. Numerical results are presented as normalized central deflections and moments in Table 3 and Table 4 respectively.

It is observed that the deformation behavior of the laminated composite plate in predefined boundary conditions is primarily affected by the in-plane and transverse shear modulus. The plates with MAT-I \& MAT-II are slightly sensitive than those with MAT-III \& MAT-IV on deflection. Similarly the effect of shear modulus is more efficient for the plates with MAT-I \& MAT-II properties in central moment measures for symmetric and anti-symmetric lamination.

Normalized stresses as another design parameter are investigated through thickness, material and lamination changes. The effect of thickness $(a / h)$ to the normalized stress measure at the center of the symmetrically $\left[0^{\circ}, 90^{\circ}, 90^{\circ}, 0^{\circ}\right]$ laminated plate of MAT-III is presented in Figure 6.

Central normalized stress deviation in axis for a thick $(a / h=10)$ and symmetrically $\quad\left[0^{\circ}, 90^{\circ}, 90^{\circ}, 0^{\circ}\right]$ laminated composite plate with four different material properties is presented in Graph 3. The effect of lamination to the normalized stress measure at the center of the symmetrically $\left[0^{\circ}, 90^{\circ}, 90^{\circ}, 0^{\circ}\right],\left[0^{\circ}, 90^{\circ}\right.$, $\left.0^{\circ}\right]$ and anti-symmetrically $\left[0^{\circ}, 90^{\circ}\right]$ laminated plate with $(a / h=10)$ and MAT-III properties is presented in Figure 7.

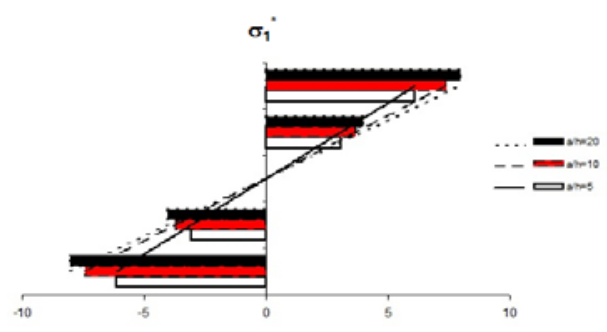

Figure 6. The effect of plate thickness to the normalized stress changes for symmetrically $\left[0^{\circ}, 90^{\circ}, 90^{\circ}, 0^{\circ}\right]$ laminated plate with MAT-III.

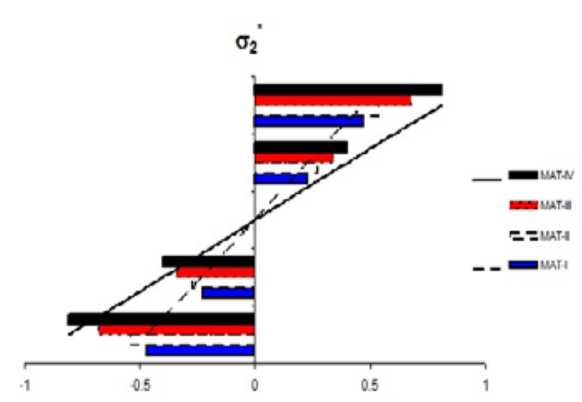

Figure 7. The effect of material properties to the central normalized stress deviation in $\left(\xi_{2}\right)$ axis for a thick $(a / h=10)$ and 
symmetrically $\left[0^{\circ}, 90^{\circ}, 90^{\circ}, 0^{\circ}\right] \quad$ laminated composite.

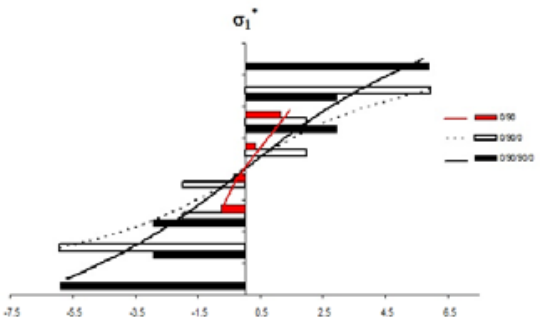

Figure 8. The effect of plate lamination to the normalized stress changes.

The normalized stress deviation in $\left(\xi_{1}\right)$ axis depending on the laminated plate thicknesses indicates the effect of $(a / h)$ ratio as presented in Figure 6. The normalized stress distribution is apparently affected by ply thickness which can be observed for thick and moderately thick regime. Not only ply thickness but also material properties are determined as another factor in the stress measure as presented in Figure 7. Moreover the changes in lamination have similar effect on the stress distribution as presented in Figure 8 since it results an increasing in the ply thicknesses.

\section{Conclusions}

Hitherto unavailable analytical solution methodology for the bilaterally clamped thick laminated plates result in a gap in the literature is presented.

The discontinuities caused by arbitrary boundary conditions are introduced by the complementary boundary constraints in the analytical methodology based on third order shear deformation theory. The complementary boundary constraints are proposed through boundary discontinuities for the complementary solution.

Because of the lack of contributive data in the literature, the numerical results are presented to provide benchmark comparisons.

The present solution is general enough to provide the complete solutions for arbitrary combination of boundary conditions, unlike the Navier or Levy type approach, which can provide only particular solution. The comparison of the results by FEA solutions that shows the predictive capabilities of the present methodology can be preferred for its adequately sensitivity and accuracy. However, to ensure the capabilities and accuracy of this new solution methodology, further studies are necessary on the shells and sandwich laminates. 
Table 3. Normalized central deflections of symmetric and anti-symmetric laminated plates for different material properties.

\begin{tabular}{cccccc} 
Lamination & $\mathbf{a} / \mathbf{h}$ & MAT-I & MAT-II & MAT-III & MAT-IV \\
\hline 5 & 21.74 & 21.51 & 20.33 & 19.73 \\
10 & 11.13 & 10.94 & 14.69 & 14.14 \\
20 & 7.99 & 7.82 & 13.19 & 12.65 \\
\hline 5 & 21.98 & 21.69 & 19.61 & 19.01 \\
10 & 10.98 & 10.78 & 14.39 & 13.85 \\
20 & 7.82 & 7.66 & 13.04 & 12.51 \\
\hline 5 & 27.48 & 67.64 & 59.76 & 131.01 \\
10 & 31.07 & 38.69 & 33.82 & 25.02 \\
20 & 103.26 & 23.02 & 14.45 & 28.58 \\
\hline
\end{tabular}

Table 4. Normalized central moments of symmetric and anti-symmetric laminated plates for different material properties.

\begin{tabular}{cccccc} 
Lamination & $\mathbf{a} / \mathbf{h}$ & MAT-I & MAT-II & MAT-III & MAT-IV \\
\hline 5 & 90.28 & 90.14 & 78.63 & 78.80 \\
10 & 109.01 & 108.44 & 87.11 & 86.82 \\
20 & 117.72 & 116.86 & 89.68 & 89.22 \\
\hline 5 & 108.29 & 107.89 & 89.07 & 88.84 \\
10 & 123.36 & 122.42 & 95.51 & 94.83 \\
20 & 128.58 & 127.38 & 97.33 & 96.49 \\
\hline 5 & 125.12 & 99.90 & 90.35 & 135.01 \\
10 & 152.96 & 232.03 & 70.19 & 99.04 \\
20 & 202.28 & 154.50 & 90.96 & 43.14 \\
\hline
\end{tabular}

\section{References}

[1] Y.G. Youssif, 2009. Non-linear Design and Control Optimization of Composite Laminated Doubly Curved Shell, Composite Structures, Vol.88, pp. 468-480, DOI:10.1016/j.compstruct.2008.0 5.020 .

[2] Zhen, W., Wanji, C. And Xiaohui, R., 2009. Refined Global-Local Higher Order Theory for Angleply Laminated Plates Under Thermo-Mechanical Loads and Finite Element Model, Composite Structures, Vol.88, pp.643-658, DOI:10.1016/j.compstruct.2008.0 6.011 .
[3] Swaminathan, K. And Patil, S.S., 2008. Analytical Solutions Using a Higher Order Refined Computational Model with 12 Degrees of Freedom for the Free Vibration Analysis of Antisymmetric Angle-ply Plates, Composite Structures, Vol.82, pp.209-216, DOI: 10.1016 / j.compstruct.2007.01.001.

[4] Sheng, H.Y. and Ye, J., 2005. State Space Solution for Axisymmetric Bending of Angle-ply Laminated Cylinder with Clamped Edges, Composite Structures, Vol.68, pp.119-128, DOI: 10.1016 /j.compstruct.2004.03.006.

[5] S.M.R. Khalili, A. Davar, and K.M. Fard, 2012. Free Vibration 
Analysis of Homogeneous Isotropic Circular Cylindrical Shells Based on a New ThreeDimensional Refined Higher Order Theory, Int.J. Mech.Sci., Vol.56, pp. 1-25, DOI: 10.1016 /j.ijmecsci.2011.11.002.

[6] Alipour, M.M., 2016. An Analytical Approach for Bending and Stress Analysis of Cross/Angle-ply Laminated Composites Under Arbitrary Non-uniform Loads and Elastic Foundations, Archives of Civil and Mechanical Engineering, Vol.16, pp. 193-210, DOI: 10.1016 /j.acme.2015.11.001.

[7] Sarangan, S., Singh, B.N., 2016. Higher Order Closed-Form Solution for the Analysis of Laminated Composite and Sandwich Plates Based on New Shear Deformation Theories, Composite Structures, Vol.138, pp. 391-403, DOI: 10.1016 /j.compstruct.2015.11.049.

[8] Sarangan, S., Singh, B.N., 2016. Improved Zigzag Theories for Laminated Composite and Sandwich Plates with Interlaminar Shear Stress Continuity, Aerospace Science and Technology, Vol:52, pp. 243-255, DOI: 10.1016 /j.ast.2016.02.034.

[9] Raghu, P., Preethi, K., Rajagopal, A. and Reddy, J.N., 2016. Nonlocal Third Order Shear Deformation Theory for Analysis of Laminated Plates Considering Surface Stress Effects, Composite Structures, Vol.139, pp.13-29, DOI: 10.1016 /j.compstruct.2015.11.068.

[10] Kurtaran H., 2015. Geometrically Nonlinear Transient Analysis of Moderately Thick Laminated Composite Shallow Shells with Differential Quadrature Method, Composite Structures, Vol. 125, pp. 605-614, DOI: 10.1016 /j.compstruct.2015.02.045.
[11] Cheung Y.K., 1976. Finite Strip Method in Structural Analysis, Publication of Pergamon Press Incorporated, 233s.

[12] Assaee H.,Hajikazemi M., Ovesy H., 2012. The Effect of Anisotropy on Post-Buckling Behavior of Laminated Plates Using SemiEnergy Finite Strip Method, Composite Structures, Vol:94, pp:1880-1885, DOI: 10.1016 /j.compstruct.2012.01.011.

[13] Ghannadpour S.A.M., Ovesy H.R., Zia-Dehkordi E., 2015. Buckling and Post-Buckling Behavior of Moderately Thick Plates Using an Exact Finite Strip, Composite Structures, Vol:147, pp:172-180, DOI: 10.1016 /j.compstruc.2014. 09.013.

[14] Kant, T. and Swaminathan, K., 2000. Estimation of Transverse / Interlaminar Stresses in Laminated Composites - a Selective Review and Survey of Current Developments, Composite Structures, Vol.449, pp.65-75, DOI: 10.1016/S02638223(99)00126-9.

[15] Nosier, A. and Bahrami, A., 2007. Interlaminar Stresses in Antisymmetric Angle-ply Laminates, Composite Structures, Vol.78, pp.18-33, DOI: 10.1016 /j.compstruct.2005.08.007.

[16] R.A. Chaudhuri, 1989. On Boundary-Discontinuous Double Fourier Series Solution to a System of Completely Coupled P.D.E.'S. Int. J. Eng. Sci. Vol.27(9), pp. 1005-1022, DOI: 10.1016 /0020-7225(89)90080-3.

[17] R.A. Chaudhuri, 2002. On the Roles of Complementary and Admissible Boundary Constraints in Fourier Solutions to BoundaryValue Problems of Completely Coupled Rth Order P.D.E.'s., J. Sound Vib., Vol.251, pp. 261-313, DOI: 10.1006/jsvi.2001.3913. 
[18] Reddy, J. N. and Liu, C. F., 1985. A Higher-Order Shear Deformation Theory of Laminated Elastic Shells, Int. J. Eng. Sci., Vol.23, pp.319-330, DOI: 10.1016/00207225(85)90051-5.

\section{Appendix-A. Definition of Equilibrium Equations.}

The equilibrium equations derived using the principles of virtual work are given as follows [19] where $q$ is the distributed transverse load, $N_{i}, M_{i}, P_{i}(i=1,2,6)$ denote stress resultants, stress couples and second stress couples respectively while $Q_{i},(i=1,2)$ represents the transverse shear stress resultants which are presented in Eqs. (A.6-A.9) by stress components.

\section{Appendices}

$\frac{\partial N_{1}}{\partial \xi_{1}}+\frac{\partial N_{6}}{\partial \xi_{2}}=0$

$\frac{\partial N_{6}}{\partial \xi_{1}}+\frac{\partial N_{2}}{\partial \xi_{2}}=0$

$\frac{\partial Q_{1}}{\partial \xi_{1}}+\frac{\partial Q_{2}}{\partial \xi_{2}}+\frac{\partial}{\partial \xi_{1}}\left(N_{1} \frac{\partial w_{0}}{\partial \xi_{1}}+N_{6} \frac{\partial w_{0}}{\partial \xi_{2}}\right)$

$+\frac{\partial}{\partial \xi_{2}}\left(N_{6} \frac{\partial w_{0}}{\partial \xi_{1}}+N_{2} \frac{\partial w_{0}}{\partial \xi_{2}}\right)+\frac{4}{3 h^{2}}\left(\frac{\partial^{2} P_{1}}{\partial \xi_{1}^{2}}+\frac{\partial^{2} P_{2}}{\partial \xi_{2}^{2}}+2 \frac{\partial^{2} P_{6}}{\partial \xi_{1} \partial \xi_{2}}\right)=-q$

$\frac{\partial M_{1}}{\partial \xi_{1}}+\frac{\partial M_{6}}{\partial \xi_{2}}-Q_{1}+\frac{4}{h^{2}} K_{1}-\frac{4}{3 h^{2}}\left(\frac{\partial P_{1}}{\partial \xi_{1}}+\frac{\partial P_{6}}{\partial \xi_{2}}\right)=0$

$\frac{\partial M_{6}}{\partial \xi_{1}}+\frac{\partial M_{2}}{\partial \xi_{2}}-Q_{2}+\frac{4}{h^{2}} K_{2}-\frac{4}{3 h^{2}}\left(\frac{\partial P_{6}}{\partial \xi_{1}}+\frac{\partial P_{2}}{\partial \xi_{2}}\right)=0$ 
in which;

$$
\begin{aligned}
& \left(N_{1}, N_{2}, N_{6}\right)=\sum_{k=1}^{N} \int_{z^{(k-1)}}^{z^{(k)}}\left(\sigma_{1}^{(k)}, \sigma_{2}^{(k)}, \sigma_{6}^{(k)}\right) d z \\
& \left(M_{1}, M_{2}, M_{6}\right)=\sum_{k=1}^{N} \int_{z^{(k-1)}}^{z^{(k)}}\left(\sigma_{1}^{(k)}, \sigma_{2}^{(k)}, \sigma_{6}^{(k)}\right) z d z \\
& \left(P_{1}, P_{2}, P_{6}\right)=\sum_{k=1}^{N} \int_{z^{(k-1)}}^{z^{(k)}}\left(\sigma_{1}^{(k)}, \sigma_{2}^{(k)}, \sigma_{6}^{(k)}\right) z^{3} d z \\
& \left(Q_{1}, Q_{2}\right)=\sum_{k=1}^{N} \int_{z^{(k-1)}}^{z^{(k)}}\left(\sigma_{4}^{(k)}, \sigma_{5}^{(k)}\right) d z
\end{aligned}
$$

$$
\begin{aligned}
& {\left[\begin{array}{l}
\sigma_{1} \\
\sigma_{2} \\
\sigma_{4} \\
\sigma_{5} \\
\sigma_{6}
\end{array}\right]=\left[\begin{array}{lllll}
\bar{C}_{11}^{(k)} & \bar{C}_{12}^{(k)} & \bar{C}_{14}^{(k)} & \bar{C}_{15}^{(k)} & \bar{C}_{16}^{(k)} \\
\bar{C}_{12}^{(k)} & \bar{C}_{22}^{(k)} & \bar{C}_{24}^{(k)} & \bar{C}_{25}^{(k)} & \bar{C}_{26}^{(k)} \\
\bar{C}_{14}^{(k)} & \bar{C}_{24}^{(k)} & \bar{C}_{44}^{(k)} & \bar{C}_{45}^{(k)} & \bar{C}_{46}^{(k)} \\
\bar{C}_{15}^{(k)} & \bar{C}_{25}^{(k)} & \bar{C}_{45}^{(k)} & \bar{C}_{55}^{(k)} & \bar{C}_{56}^{(k)} \\
\bar{C}_{16}^{(k)} & \bar{C}_{26}^{(k)} & \bar{C}_{46}^{(k)} & \bar{C}_{56}^{(k)} & \bar{C}_{66}^{(k)}
\end{array}\right]} \\
& \frac{\partial u_{1}}{\partial \xi_{1}}+z\left[\frac{\partial \phi_{1}}{\partial \xi_{1}}-z^{2} \frac{4}{3 h^{2}}\left(\frac{\partial \phi_{1}}{\partial \xi_{1}}+\frac{\partial^{2} u_{3}}{\partial \xi_{1}^{2}}\right)\right] \\
& \frac{\partial u_{2}}{\partial \xi_{2}}+z\left[\frac{\partial \phi_{2}}{\partial \xi_{2}}-z^{2} \frac{4}{3 h^{2}}\left(\frac{\partial \phi_{2}}{\partial \xi_{2}}+\frac{\partial^{2} u_{3}}{\partial \xi_{2}^{2}}\right)\right] \\
& \cdot \frac{\partial u_{2}}{\partial \xi_{1}}+\frac{\partial u_{1}}{\partial \xi_{2}}+z\left[\frac{\partial \phi_{1}}{\partial \xi_{2}}+\frac{\partial \phi_{2}}{\partial \xi_{1}}-z^{2} \frac{4}{3 h^{2}}\left(\frac{\partial \phi_{1}}{\partial \xi_{2}}+\frac{\partial \phi_{2}}{\partial \xi_{1}}+2 \frac{\partial^{2} u_{3}}{\partial \xi_{1} \partial \xi_{2}}\right)\right] \\
& \phi_{2}+\frac{\partial u_{3}}{\partial \xi_{2}}-z^{2} \frac{4}{h^{2}}\left(\phi_{2}+\frac{\partial u_{3}}{\partial \xi_{2}}\right) \\
& \phi_{1}+\frac{\partial u_{3}}{\partial \xi_{1}}-z^{2} \frac{4}{h^{2}}\left(\phi_{1}+\frac{\partial u_{3}}{\partial \xi_{1}}\right)
\end{aligned}
$$


For the most general anisotropic case, elasticity tensor (stiffness matrix) components $\left[\bar{C}_{i, j}^{(k)}\right]$ can be determined as follows according to material properties of the $k^{\text {th }}$ lamina.

$$
\begin{aligned}
& \bar{C}_{11}^{(k)}=C_{11}^{(k)} \cos ^{4} \theta^{(k)}-4 C_{16}^{(k)} \cos ^{3} \theta^{(k)} \sin \theta^{(k)} \\
& +2\left(C_{12}^{(k)}+2 C_{66}^{(k)}\right) \cos ^{2} \theta^{(k)} \sin ^{2} \theta^{(k)}-4 C_{26}^{(k)} \cos \theta^{(k)} \sin ^{3} \theta^{(k)}+C_{22}^{(k)} \sin ^{4} \theta^{(k)} \\
& \bar{C}_{12}^{(k)}=C_{12}^{(k)} \cos ^{4} \theta^{(k)}+2\left(C_{16}^{(k)}-C_{26}^{(k)}\right) \cos ^{3} \theta^{(k)} \sin \theta^{(k)} \\
& +\left(C_{11}^{(k)}+C_{22}^{(k)}-4 C_{66}^{(k)}\right) \cos ^{2} \theta^{(k)} \sin ^{2} \theta^{(k)} \\
& +2\left(C_{26}^{(k)}-C_{16}^{(k)}\right) \cos \theta^{(k)} \sin ^{3} \theta^{(k)}+C_{12}^{(k)} \sin ^{4} \theta^{(k)} \\
& \bar{C}_{14}^{(k)}=C_{14}^{(k)} \cos ^{3} \theta^{(k)}+\left(C_{15}^{(k)}-2 C_{46}^{(k)}\right) \cos ^{2} \theta^{(k)} \sin \theta^{(k)} \\
& +\left(C_{24}^{(k)}-2 C_{56}^{(k)}\right) \cos \theta^{(k)} \sin ^{2} \theta^{(k)}+C_{25}^{(k)} \sin ^{3} \theta^{(k)} \\
& \bar{C}_{15}^{(k)}=C_{15}^{(k)} \cos ^{3} \theta^{(k)}-\left(C_{14}^{(k)}+2 C_{56}^{(k)}\right) \cos ^{2} \theta^{(k)} \sin \theta^{(k)} \\
& +\left(C_{25}^{(k)}+2 C_{46}^{(k)}\right) \cos \theta^{(k)} \sin ^{2} \theta^{(k)}-C_{24}^{(k)} \sin ^{3} \theta^{(k)} \\
& \bar{C}_{16}^{(k)}=C_{16}^{(k)} \cos ^{4} \theta^{(k)}+\left(C_{11}^{(k)}-C_{12}^{(k)}-2 C_{66}^{(k)}\right) \cos ^{3} \theta^{(k)} \sin \theta^{(k)} \\
& +3\left(C_{26}^{(k)}-C_{16}^{(k)}\right) \cos ^{2} \theta^{(k)} \sin ^{2} \theta^{(k)}+\left(2 C_{66}^{(k)}+C_{12}^{(k)}-C_{22}^{(k)}\right) \cos \theta^{(k)} \sin ^{3} \theta^{(k)} \\
& -C_{26}^{(k)} \sin ^{4} \theta^{(k)} \\
& \bar{C}_{22}^{(k)}=C_{22}^{(k)} \cos ^{4} \theta^{(k)}+4 C_{26}^{(k)} \cos ^{3} \theta^{(k)} \sin \theta^{(k)}+2\left(C_{12}^{(k)}+2 C_{66}^{(k)}\right) \cos ^{2} \theta^{(k)} \sin ^{2} \theta^{(k)} \\
& +4 C_{16}^{(k)} \cos \theta^{(k)} \sin ^{3} \theta^{(k)}+C_{11}^{(k)} \sin ^{4} \theta^{(k)} \\
& \bar{C}_{24}^{(k)}=C_{24}^{(k)} \cos ^{3} \theta^{(k)}+\left(C_{25}^{(k)}+2 C_{46}^{(k)}\right) \cos ^{2} \theta^{(k)} \sin \theta^{(k)}+\left(C_{14}^{(k)}+2 C_{56}^{(k)}\right) \cos \theta^{(k)} \sin ^{2} \theta^{(k)} \\
& +C_{15}^{(k)} \sin ^{3} \theta^{(k)} \\
& \bar{C}_{25}^{(k)}=C_{25}^{(k)} \cos ^{3} \theta^{(k)}+\left(2 C_{56}^{(k)}-C_{24}^{(k)}\right) \cos ^{2} \theta^{(k)} \sin \theta^{(k)}+\left(C_{15}^{(k)}-2 C_{46}^{(k)}\right) \cos \theta^{(k)} \sin ^{2} \theta^{(k)} \\
& -C_{14}^{(k)} \sin ^{3} \theta^{(k)} \\
& \bar{C}_{26}^{(k)}=C_{26}^{(k)} \cos ^{4} \theta^{(k)}+\left(C_{12}^{(k)}-C_{22}^{(k)}+2 C_{66}^{(k)}\right) \cos ^{3} \theta^{(k)} \sin \theta^{(k)} \\
& +3\left(C_{16}^{(k)}-C_{26}^{(k)}\right) \cos ^{2} \theta^{(k)} \sin ^{2} \theta^{(k)}+\left(C_{11}^{(k)}-C_{12}^{(k)}-2 C_{66}^{(k)}\right) \cos \theta^{(k)} \sin ^{3} \theta^{(k)} \\
& -C_{16}^{(k)} \sin ^{4} \theta^{(k)}
\end{aligned}
$$




$$
\begin{aligned}
\bar{C}_{44}^{(k)}= & C_{44}^{(k)} \cos ^{2} \theta^{(k)}+C_{55}^{(k)} \sin ^{2} \theta^{(k)}+2 C_{45}^{(k)} \sin \theta^{(k)} \cos \theta^{(k)} \\
\bar{C}_{45}^{(k)}= & C_{45}^{(k)}\left(\cos ^{2} \theta^{(k)}-\sin ^{2} \theta^{(k)}\right)+\left(C_{55}^{(k)}-C_{44}^{(k)}\right) \sin \theta^{(k)} \cos \theta^{(k)} \\
\bar{C}_{46}^{(k)}= & C_{46}^{(k)} \cos ^{3} \theta^{(k)}+\left(C_{56}^{(k)}+C_{14}^{(k)}-C_{24}^{(k)}\right) \cos ^{2} \theta^{(k)} \sin \theta^{(k)} \\
& +\left(C_{15}^{(k)}-C_{25}^{(k)}-C_{46}^{(k)}\right) \cos \theta^{(k)} \sin ^{2} \theta^{(k)}-C_{56}^{(k)} \sin ^{3} \theta^{(k)} \\
\bar{C}_{55}^{(k)}= & C_{55}^{(k)} \cos ^{2} \theta^{(k)}+C_{44}^{(k)} \sin ^{2} \theta^{(k)}-2 C_{45}^{(k)} \sin \theta^{(k)} \cos \theta^{(k)} \\
\bar{C}_{56}^{(k)}= & C_{56}^{(k)} \cos ^{3} \theta^{(k)}+\left(C_{15}^{(k)}-C_{25}^{(k)}-C_{46}^{(k)}\right) \cos ^{2} \theta^{(k)} \sin ^{(k)} \\
& +\left(C_{24}^{(k)}-C_{14}^{(k)}-C_{56}^{(k)}\right) \cos \theta^{(k)} \sin ^{2} \theta^{(k)}+C_{46}^{(k)} \sin ^{3} \theta^{(k)} \\
& \bar{C}_{66}^{(k)}=2 \\
& 2\left(C_{16}^{(k)}-C_{26}^{(k)}\right) \cos ^{3} \theta^{(k)} \sin ^{(k)}+\left(C_{11}^{(k)}+C_{22}^{(k)}-2 C_{12}^{(k)}-2 C_{66}^{(k)}\right) \cos ^{2} \theta^{(k)} \sin ^{2} \theta^{(k)} \\
& +2\left(C_{26}^{(k)}-C_{16}^{(k)}\right) \cos ^{(k)} \sin ^{3} \theta^{(k)}+C_{66}^{(k)}\left(\cos ^{4} \theta^{(k)}+\sin ^{4} \theta^{(k)}\right)
\end{aligned}
$$

The components of stiffness matrix are presented below as a constitutive relation set depending on properties of each ply.

$$
\begin{aligned}
& C_{11}^{(k)}=\frac{E_{1}^{(k)}}{1-v_{12}^{(k)} v_{21}^{(k)}}, \quad C_{22}^{(k)}=\frac{E_{2}^{(k)}}{1-v_{12}^{(k)} v_{21}^{(k)}}, \\
& C_{12}^{(k)}=C_{21}^{(k)}=v_{21}^{(k)} C_{11}^{(k)}=v_{12}^{(k)} C_{22}^{(k)}, \\
& C_{66}^{(k)}=G_{12}^{(k)}, \quad C_{44}^{(k)}=G_{13}^{(k)}, \quad C_{55}^{(k)}=G_{23}^{(k)}
\end{aligned}
$$

Here $E_{1}^{(k)}$ and $E_{2}^{(k)}$ are the in-plane Young's moduli in $\left(\xi_{1}\right)$ and $\left(\xi_{2}\right)$ axes for the $k^{\text {th }}$ lamina respectively. $G_{12}^{(k)}$ denotes in-plane shear modulus, $G_{13}^{(k)}$ and $G_{23}^{(k)}$ are transverse shear moduli in the $\left(\xi_{1}-\xi_{3}\right)$ and $\left(\xi_{2}-\xi_{3}\right)$ planes, respectively, while $v_{12}^{(k)}$ is major Poisson's ratio on the $\left(\xi_{1}-\xi_{2}\right)$ plane. 
Appendix-B. Definition of the Elements of $\left[K_{i j}\right]$ in Equation (2).

$$
\begin{aligned}
& K_{11}=A_{11} \frac{\partial^{2}}{\partial \xi_{1}^{2}}+2 A_{16} \frac{\partial^{2}}{\partial \xi_{1} \partial \xi_{2}}+A_{66} \frac{\partial^{2}}{\partial \xi_{2}^{2}} \\
& K_{12}=A_{16} \frac{\partial^{2}}{\partial \xi_{1}^{2}}+\left(A_{12}+A_{66}\right) \frac{\partial^{2}}{\partial \xi_{1} \partial \xi_{2}}+A_{26} \frac{\partial^{2}}{\partial \xi_{2}^{2}} \\
& K_{13}=-\frac{4}{3 h^{2}} E_{11} \frac{\partial^{3}}{\partial \xi_{1}^{3}}-\frac{4}{h^{2}} E_{16} \frac{\partial^{3}}{\partial \xi_{1}^{2} \partial \xi_{2}}+\left(\frac{8}{3 h^{2}} E_{66}-\frac{4}{3 h^{2}} E_{12}\right) \frac{\partial^{3}}{\partial \xi_{1} \partial \xi_{2}^{2}} \\
& -\frac{4}{3 h^{2}} E_{26} \frac{\partial^{3}}{\partial \xi_{2}^{3}} \\
& K_{14}=\left(B_{11}-\frac{4}{3 h^{2}} E_{11}\right) \frac{\partial^{2}}{\partial \xi_{1}^{2}}+\left(2 B_{16}-\frac{8}{3 h^{2}} E_{16}\right) \frac{\partial^{2}}{\partial \xi_{1} \partial \xi_{2}}+\left(B_{66}-\frac{4}{3 h^{2}} E_{66}\right) \frac{\partial^{2}}{\partial \xi_{2}^{2}} \\
& K_{15}=\left(B_{16}-\frac{4}{3 h^{2}} E_{16}\right) \frac{\partial^{2}}{\partial \xi_{1}^{2}}+\left(B_{12}-\frac{4}{3 h^{2}} E_{12}+B_{66}-\frac{4}{3 h^{2}} E_{66}\right) \frac{\partial^{2}}{\partial \xi_{1} \partial \xi_{2}}+\left(B_{26}-\frac{4}{3 h^{2}} E_{26}\right) \frac{\partial^{2}}{\partial \xi_{2}^{2}} \\
& K_{21}=A_{16} \frac{\partial^{2}}{\partial \xi_{1}^{2}}+\left(A_{66}+A_{12}\right) \frac{\partial^{2}}{\partial \xi_{1} \partial \xi_{2}} \\
& K_{22}=A_{66} \frac{\partial^{2}}{\partial \xi_{1}^{2}}+A_{26} \frac{\partial^{2}}{\partial \xi_{1} \partial \xi_{2}}+A_{22} \frac{\partial^{2}}{\partial \xi_{2}^{2}} \\
& K_{23}=\frac{4}{h^{2}} E_{26} \frac{\partial}{\partial \xi_{1}}-\frac{4}{3 h^{2}} E_{12} \frac{\partial^{3}}{\partial \xi_{1}^{3}}-\frac{4}{h^{2}} E_{26} \frac{\partial^{3}}{\partial \xi_{1} \partial \xi_{2}^{2}}-\left(\frac{8}{3 h^{2}} E_{66}+\frac{4}{3 h^{2}} E_{12}\right) \frac{\partial^{3}}{\partial \xi_{1}^{2} \partial \xi_{2}} \\
& K_{24}=\left(B_{16}-\frac{4}{3 h^{2}} E_{16}\right) \frac{\partial^{2}}{\partial \xi_{1}^{2}}+\left(B_{66}+B_{12}-\frac{4}{3 h^{2}} E_{66}-\frac{4}{3 h^{2}} E_{12}\right) \frac{\partial^{2}}{\partial \xi_{1} \partial \xi_{2}}+\left(B_{26}-\frac{4}{3 h^{2}} E_{26}\right) \frac{\partial^{2}}{\partial \xi_{2}^{2}} \\
& K_{25}=\left(B_{66}-\frac{4}{3 h^{2}} E_{66}\right) \frac{\partial^{2}}{\partial \xi_{1}^{2}}+\left(B_{16}-\frac{4}{3 h^{2}} E_{16}\right) \frac{\partial^{2}}{\partial \xi_{1} \partial \xi_{2}}+\left(B_{22}-\frac{4}{3 h^{2}} E_{22}\right) \frac{\partial^{2}}{\partial \xi_{2}^{2}}
\end{aligned}
$$




$$
\begin{aligned}
& K_{31}=\frac{4}{3 h^{2}} E_{11} \frac{\partial^{3}}{\partial \xi_{1}^{3}}+\frac{4}{3 h^{2}} E_{16} \frac{\partial^{3}}{\partial \xi_{1}^{2} \partial \xi_{2}}+\left(\frac{4}{3 h^{2}} E_{12}+\frac{8}{3 h^{2}} E_{66}\right) \frac{\partial^{3}}{\partial \xi_{1} \partial \xi_{2}^{2}}+A_{22} \frac{\partial^{3}}{\partial \xi_{2}^{3}} \\
& K_{32}=\frac{4}{3 h^{2}} E_{16} \frac{\partial^{3}}{\partial \xi_{1}^{3}}+\left(\frac{4}{3 h^{2}} E_{12}+\frac{8}{3 h^{2}} E_{66}\right) \frac{\partial^{3}}{\partial \xi_{1}^{2} \partial \xi_{2}}+\frac{4}{3 h^{2}} E_{26} \frac{\partial^{3}}{\partial \xi_{1} \partial \xi_{2}^{2}}+\frac{4}{3 h^{2}} E_{22} \frac{\partial^{3}}{\partial \xi_{2}^{3}} \\
& K_{33}=-\frac{16}{9 h^{4}} H_{11} \frac{\partial^{4}}{\partial \xi_{1}^{4}}+\left(-\frac{32}{9 h^{4}} H_{12}-\frac{64}{9 h^{4}} H_{66}\right) \frac{\partial^{4}}{\partial \xi_{1}^{2} \partial \xi_{2}^{2}}-\frac{16}{9 h^{4}} H_{22} \frac{\partial^{4}}{\partial \xi_{2}^{4}}-\frac{64}{9 h^{4}} H_{26} \frac{\partial^{4}}{\partial \xi_{2} \partial \xi_{2}^{3}} \\
& +\left(A_{55}-\frac{8}{h^{2}} D_{55}+\frac{16}{h^{4}} F_{55}\right) \frac{\partial^{2}}{\partial \xi_{1}^{2}}+\left(2 A_{45}-\frac{16}{h^{2}} D_{45}+\frac{32}{h^{4}} F_{45}\right) \frac{\partial^{2}}{\partial \xi_{1} \partial \xi_{2}} \\
& +\left(A_{44}-\frac{8}{h^{2}} D_{44}+\frac{16}{h^{2}} F_{44}\right) \frac{\partial^{2}}{\partial \xi_{2}^{2}}
\end{aligned}
$$

$$
\begin{aligned}
& K_{34}=\left(A_{55}-\frac{8}{h^{2}} D_{55}+\frac{16}{h^{4}} F_{55}\right) \frac{\partial}{\partial \xi_{1}}+\left(A_{45}-\frac{8}{h^{2}} D_{45}+\frac{16}{h^{4}} F_{45}\right) \frac{\partial}{\partial \xi_{2}} \\
& +\left(\frac{4}{3 h^{2}} F_{11}-\frac{16}{9 h^{4}} H_{11}\right) \frac{\partial^{3}}{\partial \xi_{1}^{3}}+\left(\frac{4}{h^{2}} F_{16}-\frac{16}{3 h^{4}} H_{16}\right) \frac{\partial^{3}}{\partial \xi_{1}^{2} \xi_{2}}+\left(\frac{4}{3 h^{2}} F_{12}-\frac{16}{9 h^{4}} H_{12}\right. \\
& \left.+\frac{8}{3 h^{2}} F_{66}-\frac{32}{9 h^{4}} H_{66}\right) \frac{\partial^{3}}{\partial \xi_{1} \xi_{2}^{2}}+\left(\frac{4}{3 h^{2}} F_{26}-\frac{16}{9 h^{4}} H_{26}\right) \frac{\partial^{3}}{\partial \xi_{2}^{3}} \\
& K_{35}=\left(A_{45}-\frac{8}{h^{2}} D_{45}+\frac{16}{h^{4}} F_{45}\right) \frac{\partial}{\partial \xi_{1}}+\left(A_{44}-\frac{8}{h^{2}} D_{44}+\frac{16}{h^{4}} F_{44}\right) \frac{\partial}{\partial \xi_{2}} \\
& +\left(\frac{4}{3 h^{2}} F_{22}-\frac{16}{9 h^{4}} H_{22}\right) \frac{\partial^{3}}{\partial \xi_{1}^{3}}+\left(\frac{4}{3 h^{2}} F_{12}-\frac{16}{9 h^{4}} H_{12}+\frac{8}{3 h^{2}} F_{66}-\frac{32}{9 h^{4}} H_{66}\right) \frac{\partial^{3}}{\partial \xi_{1}^{2} \xi_{2}} \\
& +\left(\frac{4}{h^{2}} F_{26}-\frac{16}{3 h^{4}} H_{26}\right) \frac{\partial^{3}}{\partial \xi_{1} \xi_{2}^{2}}+\left(\frac{4}{h^{2}} F_{26}-\frac{16}{3 h^{4}} H_{26}\right) \frac{\partial^{3}}{\partial \xi_{2}^{3}}
\end{aligned}
$$

$$
\begin{aligned}
& K_{41}=B_{11} \frac{\partial^{2}}{\partial \xi_{1}^{2}}+\left(2 B_{16}-\frac{4}{h^{2}} E_{12}-\frac{4}{h^{2}} E_{16}\right) \frac{\partial^{2}}{\partial \xi_{1} \partial \xi_{2}}+\left(B_{66}-\frac{4}{h^{2}} E_{26}\right) \frac{\partial^{2}}{\partial \xi_{2}^{2}} \\
& K_{42}=\left(B_{16}-\frac{4}{h^{2}} E_{16}\right) \frac{\partial^{2}}{\partial \xi_{1}^{2}}+\left(B_{12}+B_{66}-\frac{4}{h^{2}} E_{26}-\frac{4}{h^{2}} E_{12}\right) \frac{\partial^{2}}{\partial \xi_{1} \partial \xi_{21}}+\left(B_{26}-\frac{4}{h^{2}} E_{22}\right) \frac{\partial^{2}}{\partial \xi_{2}^{2}}
\end{aligned}
$$


V.Alankaya / Bending Analysis of Bilaterally Clamped Thick Cross-Ply Composite Plates

$$
\begin{aligned}
& K_{43}=\left(-A_{55}+\frac{16}{3 h^{2}} D_{55}-\frac{16}{3 h^{4}} F_{55}\right) \frac{\partial}{\partial \xi_{1}}+\left(-A_{45}+\frac{16}{3 h^{2}} D_{45}-\frac{16}{3 h^{4}} F_{45}\right) \frac{\partial}{\partial \xi_{2}}-\frac{16}{9 h^{4}} H_{11} \frac{\partial^{3}}{\partial \xi_{1}^{3}} \\
& +\left(\frac{16}{3 h^{4}} H_{12}-\frac{32}{3 h^{4}} H_{26}-\frac{8}{3 h^{2}} F_{66}\right) \frac{\partial^{3}}{\partial \xi_{1} \partial \xi_{2}^{2}}+\left(-\frac{32}{3 h^{4}} H_{16}-\frac{16}{3 h^{4}} H_{12}-\frac{4}{3 h^{4}} F_{16}\right) \frac{\partial^{3}}{\partial \xi_{1}^{2} \partial \xi_{2}} \\
& +\left(\frac{16}{3 h^{2}} H_{11}-\frac{4}{h^{2}} F_{11}\right) \frac{\partial^{3}}{\partial \xi_{2}^{3}} \\
& K_{44}=\left(D_{11}-\frac{16}{3 h^{2}} F_{11}-\frac{16}{3 h^{4}} H_{11}\right) \frac{\partial^{2}}{\partial \xi_{1}^{2}}+\left(2 D_{16}-\frac{20}{3 h^{2}} F_{16}-\frac{4}{h^{2}} F_{12}+\frac{16}{3 h^{4}} H_{12}\right. \\
& \left.-\frac{16}{3 h^{4}} H_{26}\right) \frac{\partial^{2}}{\partial \xi_{1} \partial \xi_{2}}+\frac{4}{3 h^{2}} E_{26} \frac{\partial^{2}}{\partial \xi_{1} \partial \xi_{2}{ }^{2}}+\left(D_{66}-\frac{4}{3 h^{2}} F_{66}-\frac{4}{h^{2}} F_{26}+\frac{16}{3 h^{4}} H_{26}\right) \frac{\partial^{2}}{\partial \xi_{2}^{2}} \\
& +\left(\frac{16}{3 h^{2}} D_{55}-\frac{16}{3 h^{4}} F_{55}-A_{55}\right) \\
& K_{45}=\left(D_{16}-\frac{16}{3 h^{2}} F_{16}+\frac{16}{3 h^{4}} H_{16}\right) \frac{\partial^{2}}{\partial \xi_{1}^{2}}+\left(\begin{array}{l}
D_{12}-\frac{4}{3 h^{2}} F_{12}+D_{66}-\frac{4}{3 h^{2}} F_{66}-\frac{4}{h^{2}} F_{26} \\
+\frac{16}{3 h^{4}} H_{26}-\frac{4}{h^{2}} F_{12}
\end{array}\right) \frac{\partial^{2}}{\partial \xi_{1} \partial \xi_{2}} \\
& +\left(D_{26}-\frac{4}{3 h^{2}} F_{26}+\frac{4}{h^{2}} F_{22}-\frac{16}{3 h^{4}} H_{22}\right) \frac{\partial^{2}}{\partial \xi_{2}^{2}}+\left(\frac{16}{3 h^{2}} D_{55}-\frac{16}{3 h^{4}} F_{55}-A_{55}\right) \\
& K_{51}=\left(B_{16}-\frac{4}{h^{2}} E_{16}\right) \frac{\partial^{2}}{\partial \xi_{1}^{2}}+\left(B_{66}+B_{12}-\frac{4}{h^{2}} E_{66}-\frac{4}{h^{2}} E_{12}\right) \frac{\partial^{2}}{\partial \xi_{1} \partial \xi_{2}}+/\left(B_{22}-\frac{4}{h^{2}} F_{26}\right) \frac{\partial^{2}}{\partial \xi_{2}^{2}} \\
& K_{52}=\left(B_{66}-\frac{4}{h^{2}} E_{66}\right) \frac{\partial^{2}}{\partial \xi_{1}^{2}}+\left(2 B_{26}-\frac{8}{3 h^{2}} E_{26}\right) \frac{\partial^{2}}{\partial \xi_{1} \partial \xi_{2}}+\left(B_{22}-\frac{4}{h^{2}} E_{22}\right) \frac{\partial^{2}}{\partial \xi_{2}^{2}} \\
& K_{53}=\left(-A_{45}+\frac{16}{3 h^{2}} D_{45}-\frac{16}{3 h^{4}} F_{45}\right) \frac{\partial}{\partial \xi_{1}}+\left(-A_{44}+\frac{16}{3 h^{2}} D_{44}-\frac{16}{3 h^{4}} F_{44}\right) \frac{\partial}{\partial \xi_{2}}-\frac{16}{9 h^{4}} H_{11} \frac{\partial^{3}}{\partial \xi_{1}^{3}} \\
& +\left(\frac{16}{3 h^{4}} H_{12}+\frac{32}{3 h^{4}} H_{66}-\frac{8}{3 h^{2}} F_{66}-\frac{4}{3 h^{2}} F_{12}\right) \frac{\partial^{3}}{\partial \xi_{1} \partial \xi_{2}^{2}}+\left(\frac{16}{h^{4}} H_{26}-\frac{4}{h^{2}} F_{26}\right) \frac{\partial^{3}}{\partial \xi_{1}^{2} \partial \xi_{2}} \\
& +\left(\frac{16}{3 h^{2}} H_{16}-\frac{4}{h^{2}} F_{16}\right) \frac{\partial^{3}}{\partial \xi_{2}^{3}}
\end{aligned}
$$




$$
\begin{aligned}
& K_{54}=\left(D_{16}-\frac{16}{3 h^{2}} F_{16}+\frac{16}{3 h^{4}} H_{16}\right) \frac{\partial^{2}}{\partial \xi_{1}^{2}}+\left(D_{66}-\frac{16}{3 h^{2}} F_{66}+D_{12}-\frac{16}{3 h^{4}} F_{12}\right. \\
& \left.-\frac{16}{3 h^{4}} H_{66}+\frac{16}{3 h^{2}} H_{12}\right) \frac{\partial^{2}}{\partial \xi_{1} \partial \xi_{2}}+\frac{4}{3 h^{2}} E_{26} \frac{\partial^{2}}{\partial \xi_{1} \partial \xi_{2}^{2}}+\left(D_{26}-\frac{16}{3 h^{2}} F_{26}+\frac{16}{3 h^{4}} H_{26}\right) \frac{\partial^{2}}{\partial \xi_{2}^{2}} \\
& +\left(\frac{16}{3 h^{2}} D_{45}-\frac{16}{3 h^{4}} F_{45}-A_{45}\right) \\
& K_{55}=\left(D_{66}-\frac{16}{3 h^{2}} F_{66}+\frac{16}{3 h^{4}} H_{66}\right) \frac{\partial^{2}}{\partial \xi_{1}^{2}}+\left(2 D_{26}-\frac{32}{3 h^{2}} F_{26}+\frac{32}{3 h^{4}} H_{26}\right) \frac{\partial^{2}}{\partial \xi_{1} \partial \xi_{2}} \\
& +\left(D_{22}-\frac{16}{3 h^{2}} F_{22}-\frac{16}{3 h^{4}} H_{22}\right) \frac{\partial^{2}}{\partial \xi_{2}^{2}}+\left(\frac{16}{3 h^{2}} D_{44}-\frac{16}{3 h^{4}} F_{44}-A_{44}\right)
\end{aligned}
$$

in which $A_{i j}, B_{i j}$, etc. are the laminate rigidities and are given as follows:

$$
\begin{aligned}
& \left(A_{i j}, B_{i j}, D_{i j}\right)=\sum_{k=1}^{N} \int_{z_{k-1}}^{z_{k}} \bar{C}_{i j}^{(k)}\left(1, z, z^{2}\right) d z \\
& \left(E_{i j}, F_{i j}, H_{i j}\right)=\sum_{k=1}^{N} \int_{z_{k-1}}^{z_{k}} \bar{C}_{i j}^{(k)}\left(z^{3}, z^{4}, z^{6}\right) d z
\end{aligned}
$$

Moreover the following definitions are prescribed for cross-ply lamination;

$$
\begin{array}{ll}
A_{16}=A_{26}=A_{45}=0, & B_{16}=B_{26}=0, \\
D_{16}=D_{26}=D_{45}=0, & E_{16}=E_{26}=0, \\
F_{16}=F_{26}=F_{45}=0, & H_{16}=H_{26}=0
\end{array}
$$

